\title{
Analysis of the Impact of Psychic Distance on the Regional Selection of Chinese Outward Foreign Direct Investment
}

\author{
Man-Yu HUANG \\ School of Business Administration, Zhongnan Univerisity of Economics and Law, Wuhan, Hubei \\ huangmanyu@vip.sina.com
}

\author{
Keywords: OFDI; Psychic Distance; Culture Distance
}

\begin{abstract}
The paper chose the seven dimensions of psychic distance ,that is language distance, religion distance, culture distance, industrialization distance, political distance, education distance and geographic distance as independent variables, and the paper analyzed the conduction mechanism to OFDI from the seven dimensions. Using China's OFDI data from 2004-2013 as dependent variables, and calculating 3 control variables demonstrate OFDI'S motivations, the paper implemented positive analysis by using regression method. Conclusion shows that language distance affects China's OFDI mostly, and the influence from political distance is the second largest, and the influence from culture distance is the smallest. That proves language barriers and political barriers are the most difficult for Chinese multinational enterprises to overcome. The linear positive correlation of industrialization distance with China's OFDI demonstrates the seeking for strategic asset plays more and more important role in China's OFDI process, and the new tendency need to be paid attention.
\end{abstract}

\section{Introduction}

Since China introduced its "Go Global" policy promoting oversea investment from 1999, Chinese outward FDI(OFDI) has experienced a significant increase. Particularly, Chinese OFDI has increase sharply since 2005.There were 16 thousand Chinese investors established 22 thousand enterprises overseas, and these enterprises spread 179 countries(regions) worldwide, the total asset of these abroad enterprises reached to 2.6 trillion dollars. Meanwhile, China's OFDI accumulated stock volume increased from 33.2 billion dollars in 2003 to 531.94 billion dollars in 2012, and net outflows from 2.85 billion dollars to 87.8 billion dollars. With the development of China's OFDI, the regional distribution of OFDI is significant, now China's OFDI mainly is located in Asia, Hong Kong (China's Special Administrative Region), Australia and South Africa. It indicate that Chinese MNCs follow a regionalization strategy rather than a global one (Rugman and Doh 2008). Several studies have been performed to discuss the development, but the role of psychic distance has largely remained unexplored.

Although some scholars advance psychic distance influences international process and decisions of MNCs, the explanatory value of the factor is uncertain, and the differences of dimensions of psychic distance to regional selection is still unknown. So, this paper aims to investigate the role of psychic distance as an explanatory factor for the regional selection of China's OFDI, in addition ,it will test to what extent the dimensions of psychic distance in terms of differences in language, religion, culture, economic development, political systems, education and geographic distance explains the choice of countries(regions). The conclusions of the paper help to explain the flow of China's OFDI from perspective of psychic distance, so to help China's MNCs understand the market environment of host countries better and accumulate experience on international operation.

\section{Literature Review}

The term 'psychic distance' was advanced by Beckerman (1956) in his empirical research on intra-European trade flows. Then scholars at the University of Uppsala began to pay attention to the role of psychic distance on international investment and business since 1970's. They defined psychic 
distance as 'the sum of factors preventing the flow of information to and from the market'.(Johanson and Vahlne, 1977) Scholars implemented a serial of researches on the measurement and application of psychic distance under the influence of the research from scholars from Uppsala University.

Researches on earlier stage advanced that the measurement of psychic distance was decided by the perception of key decision-makers. This approach was merited in that many of management decisions associated with psychic distance, such as the decisions on where to invest and how much to invest were based on the managers' perceptions on the psychic distance. However, this approach has its limitations. Firstly, researchers rarely have the chances to survey a decision-maker's perceptions prior to a critical decision is made, researchers measurement always tend to be perceived psychic distance after decisions are made. This introduces a problem of discerning whether the 'perceptions' influenced the 'decision', or whether the 'post-decision experience' influenced the 'perceptions'. Secondly, the age, experience, characteristics, education level tend to influence the decision-makers judgment, so the measurement will lead the instability and heterogeneity of the measurement of psychic distance.

Scholars began to use composite index to measure psychic distance from macro perspective because of the limitations above. Some scholars used composite index of Hofstede's cultural dimensions as the sole indicator of psychic distance in their empirical analysis(Kogut and Singh (1988)).However, there seems to be a growing agreement that culture is only one dimension of psychic distance and that the use of Hofstede's dimensions as a single indicator to psychic distance is misleading (Dow 2000; Dow and Karunaratna 2006). For this reason, several authors have developed indicators to estimate psychic distance from counties levels. Dow and Karunaratna (2006) suggest focusing on measuring the factors that influence managerial perception ,they propose seven dimensions and measure these by multiple indicators, using data from publicly available statistics, as well as sociological constructs, like Hofstede’s (1980) cultural dimensions.

The application of psychic distance mainly focus on the choices of market abroad, trade flow, foreign direct investment and entry modes of MNCs. However, despite the heaps of studies on psychic distance, the role of psychic distance for the choice of market abroad has largely remained unexplored. Especially for the outward FDI by Chinese companies, the explanatory value of psychic distance for understanding OFDI from developing countries is still unknown.

So, the aim of this paper is to investigate the traditional role of psychic distance as an explanatory factor for the internationalization path of MNCs from developed countries and see to what extent it can explain the internationalization of Chinese MNCs. In particular, the paper aims to test what extent psychic distance in terms of differences in language, religion, culture, economic development, political systems, education, and geographic distance explains the investment behavior of Chinese companies.

\section{Measurement of Psychic Distance and the Influences to the Choices of Market Abroad}

\section{The Measurement of Psychic Distance}

Here we drew upon the psychic distance measurement developed by Dow and Karunaratna(2006),because this approach had been the basis for further development of research on the concept of psychic distance and its antecedents (e.g., Håkanson and Ambos 2010), and was much cited in empirical studies including psychic distance or related variables showing that it had become a main approach to measuring these concepts. They proposed seven dimensions and measure these by multiple indicators, using data from publicly available statistics, as well as sociological constructs, like Hofstede's 1980 cultural dimensions. The seven dimensions include language, religion, culture, economic development, political systems, education, and geographic distance.

\section{The Influences of the Dimensions of Psychic Distance to the Choices of Market Abroad}

\section{Influences of Differences of Language to the Choice of OFDI}

Language differences between countries tend to increase both the costs and the risks of a transaction. As a result, language is a key component of psychic distance, and influences 
international expansion patterns.

\section{Influences of Differences of Religion to the Choice of OFDI}

Religion is closely associated with culture, attitudes and norms (Boyacigiller, 1990), and it is considered a major component of conflict between different cultural groupings (Triandis, 2000). It forms a foundation upon which people assess whether certain behaviors are desirable and acceptable. Thus, religion undeniably plays a major role in the way people communicate and interact. Differences in religion will therefore increase the cost of a transaction and risk of misunderstandings, and are likely to reduce the trading intensity between countries.

\section{Influences of Differences of Culture to the Choice of OFDI}

Culture influences not only people's behavior but also their communication style and the interpretations of information. Large cultural distances between two groups of individuals will increase the cost of interpreting information flows between the parties, and also increase the risk of misinterpretation (Boyacigiller,1990). These increases in transaction costs, both real and perceived, will in turn influence a manager's perception of the attractiveness of doing business with a group of individuals.

\section{Influences of Differences of Industrial Development to the Choice of OFDI}

Differences of industrial development lead to differences of the nature of a person's employment, and the nature employment is likely to influence how we communicate. Moreover, the norms of business-to-business communication and interaction are also likely to be heavily influenced by the nature of the economy, and thus by the level of economic development.

\section{Influences of Differences of Political Systems to the Choice of OFDI}

Dramatic differences in political systems tend to increase the costs and uncertainty of communications between governments and enterprises. Governments also play a key role in policing various business-to-business and business-to-consumer interactions. As a result, differences in political systems increase the risk of doing business in a foreign country, thus influencing market selection decisions.

\section{Influences of Differences of Education Levels to the Choice of OFDI}

Differences in education levels between markets might increase the risk and uncertainty of a manager properly understanding and communicating with the market. Furthermore, this is likely to impact on market preferences, and thus trade flows.

\section{Influences of Differences of Geographic Distance to the Choice of OFDI}

Although advances in telecommunications have reduced the cost of talking to people in other continents, differences of geographic distance lead to the differences in time zones, so this create uncertainty about the ability for rapid communication.

In conclusion, the influences of the above seven dimensions of psychic distance to the choices of market abroad can be illustrated as follows (see Figure 1). 


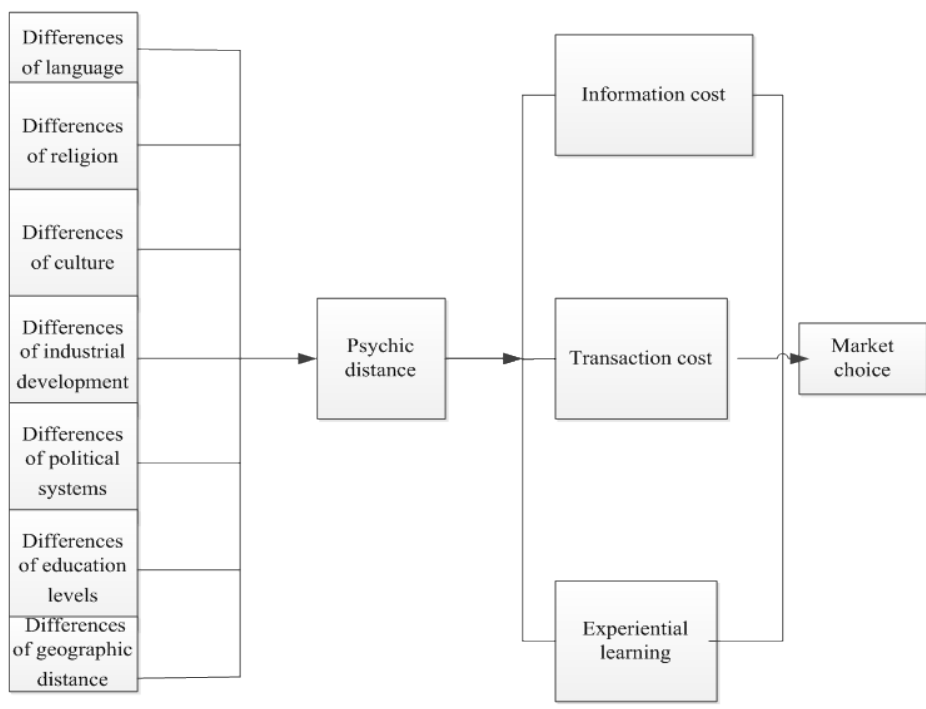

Figure 1 Complex influences of dimensions of psychic distance to the market choice of OFDI

\section{Empircal Analysis}

\section{Measurement of Psychic Distance and Data}

The paper used the research from Dow and Karunaratna (2006) in measuring the respective psychic distance dimensions. ${ }^{1}$ And the measurement of cultural distance was obtained from Hofestede's research center ${ }^{2}$. The geographic distance was measured by the distance between capitals of each two countries, and we used logarithmic process after we got the data.

\section{Data of China's OFDI}

The data of China's OFDI was retrieved from China Foreign Investment Statistics Bulletin that compiled by The Ministry of Commerce, the National Bureau of statistics and the State Administration of foreign exchange. We used the natural logarithm of the mean Chinese OFDI 2004-2013 in our models. This study only considered those countries and regions with China's OFDI stock reached 100 million dollars.104 countries and regions meet the requirement, and 46 of them didn't have complete data, so there remained 58 countries or regions as the 46 was removed.

\section{Control Variables and Data}

Following the work by Buckley et al. (2007) and Blomkvist (2013), we included control variables representing different motives of Chinese OFDI. Strategic asset seeking, market seeking and resource seeking are the main motives, so we used the total annual patent registration (LPAT) in the host country to measure strategic asset seeking FDI, GDP(LGDP) of the host country to control for market seeking Chinese OFDI, the ratio of ore and metal exports(LORE) to control for resource seeking.

\section{Econometric Model}

Here we built 3 econometric models:

$$
\begin{aligned}
& \text { OFDI }_{\mathrm{it}}=\mathrm{C}+\beta_{1} \mathrm{LGDP}_{\mathrm{it}}+\beta_{2} \mathrm{LORE}_{\mathrm{it}}+\beta_{3} \mathrm{LPAT}_{\mathrm{it}}+\varepsilon_{\mathrm{it}} . \\
& \mathrm{OFDI}_{\mathrm{it}}=\mathrm{C}+\beta_{1} \mathrm{LGDP}_{\mathrm{it}}+\beta_{2} \mathrm{LORE}_{\mathrm{it}}+\beta_{3} \mathrm{LPAT}_{\mathrm{it}}+\beta_{4} \mathrm{PSD}_{\mathrm{it}}+\varepsilon_{\mathrm{it}} .
\end{aligned}
$$

OFDI $_{\mathrm{it}}=\mathrm{C}+\beta_{1} \mathrm{LGDP}_{\mathrm{it}}+\beta_{2} \mathrm{LORE}_{\mathrm{it}}+\beta_{3} \mathrm{LPAT}_{\mathrm{it}}+\beta_{4} \mathrm{LAND}_{\mathrm{it}}+\beta_{5} \mathrm{RELD}_{\mathrm{it}}+\beta_{6} \mathrm{CULD}_{\mathrm{it}}+\beta_{7} \mathrm{ECOD}_{\mathrm{it}}+\beta_{8} \mathrm{POLD}_{\mathrm{it}}+$

$$
\beta_{9} \mathrm{EDUD}_{\mathrm{it}}+\beta_{10} \mathrm{GEOD}_{\mathrm{it}}+\varepsilon_{\mathrm{it}}
$$

\footnotetext{
(1) Dow and Karunaratna calculate differences of language, education, industrial development, political system and education levels between 120 countries, all the data can be retrieved from https://sites.google.com/site/ddowresearch/.

(2) Hofestede offers six dimensions to measure cultural differences, all the data can be obtained from http://www.geert-hofstede.com. We use CULDj $=\sum_{\mathrm{i}=1}^{6}\left[\left(\mathrm{I}_{\mathrm{ij}-} \mathrm{I}_{\mathrm{im}}\right)^{2} / \mathrm{V}_{\mathrm{i}}\right] / 6$ to calculate cultural differences after we get the six dimensions from the website.
} 


\section{Findings and Discussion}

The correlation matrix of the dependent and independent variables is shown in Table 2

Table 1 Outcome of regression analysis

\begin{tabular}{|l|l|l|l|}
\hline & MODEL 1 & MODEL 2 & MODEL 3 \\
\hline LGDP & $0.124(0.301)$ & $0.381(1.294)$ & $0.243(0.889)$ \\
\hline LORE & $0.052(0.642)$ & $0.004(0.163)$ & $0.021(1.130)$ \\
\hline LPAT & $0.383^{*}(1.713)$ & $0.225(1.112)$ & $0.337^{* * *}(1.745)$ \\
\hline PSD & & $-0.031^{* *}(-2.041)$ & \\
\hline LAND & & & $-1.459^{* * *}(-1.969)$ \\
\hline RELD & & & $1.553(1.131)$ \\
\hline CULD & & & $-0.287^{* *}(-2.481)$ \\
\hline ECOD & & & $1.022^{*}(1.714)$ \\
\hline POLD & & & $-1.173^{* *}(-2.431)$ \\
\hline EDUD & & & $0.156(0.228)$ \\
\hline GEOD & & & $-0.532(-1.259)$ \\
\hline F & $2.912^{* *}$ & $3.472^{* *}$ & $4.987^{* * *}$ \\
\hline $\mathrm{R}^{2}$ & 0.211 & 0.320 & 0.652 \\
\hline
\end{tabular}

t-values in parentheses; ${ }^{*} \mathrm{p}<0.05 ; * * \mathrm{p}<0.01 ; * * * \mathrm{p}<0.001$

R2 of table 2 shows the extent of the explanation of the dependent variable is gradually improved fromthe model 1, model 2, model 3, and model 3 has the highest degree of interpretation.

Table 1 shows psychic distance, differences of language, differences of culture, differences of politics related negatively to China's OFDI, differences of religions, differences of education and geographic distance didn't relate to China's OFDI, while differences of industrial development related positively with China's OFDI.

Model 3 verifies that differences of language, differences of culture and differences of politics related negatively to China's OFDI, and differences of language have the greatest influence, differences of politics are ranked the second, and differences of culture have the minimal impact, while differences of religion, differences of education and geographical distance have no significant linear relationship with China's OFDI. The most remarkable result is that contrary to the previous theoretical analysis, differences of industrial development relate positively with China's OFDI, this shows that the motivations of seeking for technology motivate the expansion of China's OFDI as most of the countries have the advanced technology are developed countries, these countries have large gap of industrial level with China, and Chinese enterprises are more likely to invest to these developed countries.

In addition, the outcome of above empirical analysis also shows that comparing with the differences of culture, differences of language and differences of politics have greater influences to the location selection of China's OFDI. Due to the special nature of Chinese language, the language barrier has became the main obstacles of China's OFDI .Therefore, training more talents who are skillful in the using of foreign languages, especially English is very important. In order to overcome the risks aroused by differences of politics, enterprises should adopt the localization of management team, work with local partners as strategic alliances or joint ventures, so as to adapt to the host country's business environment as soon as possible.

\section{References}

[1]Arora A. and Fosfuri A., Wholly Owned Subsidiary Versus Technology Licensing in the Worldwide Chemical Industry.Journal of International Business Studies, 2000.Vol.31, No.4,:555-572.

[2]Beckerman W., Distance and the Pattern of Intra-European Trade. Review of Economics and Statistics, 1956.(38):31-40. 
[3]Blomkvist K.and Drogendijk R., The Impact of Psychic Distance on Chinese Outward Foreign Direct Investments, Management International Review, 2013.(53):659-686.

[4] Brewer P.A., Psychic Distance and Australian Export Market Selection,Australian Journal of Management, 2007,(32), :73-94.

[5]Buckley P. J., Clegg L.J., Cross.A.R., The Determinants of Chinese Outward Foreign Direct Investment, Journal of International Business Studies, 38(4): 499-518.

[6] Dow D., A Note on Psychic Distance and Export Market Selection, Journal of International Marketing.2000,(8): 51-64.

[7] Dow D. and Karunaratna A., Developing a multidimensional Instrument to Measure Psychic Distance Stimuli,Journal of International Business Studies,2006,37(5):pp.578-602.

[8] Evans J. and Treadgold A. and Mavondo F., Explaining Export Development through Psychic Distance,International Marketing Review, 2000,17(2):164-168.

[9]Hofstede G. and Bond M.H., The Confucius Connection: from Cultural Roots to Economic Growth, Organizational Dynamics,1988,16(4):4-21. 